\title{
Effects of distinctive encoding on correct and false memory: A meta-analytic review of costs and benefits and their origins in the DRM paradigm
}

\author{
Mark J. Huff • Glen E. Bodner • Jonathan M. Fawcett \\ Published online: 23 May 2014 \\ (C) The Author(s) 2014. This article is published with open access at SpringerLink.com
}

\begin{abstract}
We review and meta-analyze how distinctive encoding alters encoding and retrieval processes and, thus, affects correct and false recognition in the Deese-RoedigerMcDermott (DRM) paradigm. Reductions in false recognition following distinctive encoding (e.g., generation), relative to a nondistinctive read-only control condition, reflected both impoverished relational encoding and use of a retrievalbased distinctiveness heuristic. Additional analyses evaluated the costs and benefits of distinctive encoding in withinsubjects designs relative to between-group designs. Correct recognition was design independent, but in a within design, distinctive encoding was less effective at reducing false recognition for distinctively encoded lists but more effective for nondistinctively encoded lists. Thus, distinctive encoding is not entirely "cost free" in a within design. In addition to delineating the conditions that modulate the effects of distinctive encoding on recognition accuracy, we discuss the utility of using signal detection indices of memory information and memory monitoring at test to separate encoding and retrieval processes.
\end{abstract}

Keywords Recognition · Distinctiveness · DRM paradigm · Encoding $\cdot$ Retrieval $\cdot$ Meta-analysis

\footnotetext{
M. J. Huff $(\bowtie)$

Department of Psychology, Washington University in St. Louis, St. Louis, MO 63130, USA

e-mail: mhuff@wustl.edu

G. E. Bodner

University of Calgary, Calgary, AB, Canada

J. M. Fawcett

MRC Cognition and Brain Sciences Unit, Cambridge, UK
}

\section{Introduction}

The finding that distinctively encoded information enjoys a memory advantage has a rich history in memory research (for reviews, see Hunt and Worthen 2006; Schmidt 1991). Nearly any memory benefit for unique stimuli or for stimuli studied in unique ways, relative to control stimuli or encoding tasks, has been attributed to distinctive processing, including effects of isolation (Kelley and Nairne 2001; von Restorff 1933), levels of processing (Craik and Lockhart 1972), generation (Slamecka and Graf 1978), production (Hopkins and Edwards 1972; MacLeod et al. 2010), item-specific processing (Hunt and Einstein 1981), and bizarreness (McDaniel and Einstein 1991). The widely applied construct of distinctiveness has been defined as the "processing of difference in the context of similarity" (Hunt 2006, p. 12). This definition of the phenomenon wisely steers clear of specifying both the processes underlying distinctiveness effects and whether they emerge at study and/or at test. Our review uses a metaanalytic approach to examine the contributions of encoding and retrieval processes to distinctiveness effects in both correct memory and false memory errors. To this end, we focused on a commonly used and powerful false memory paradigm the Deese-Roediger-McDermott (DRM) paradigm (Deese 1959; Roediger and McDermott 1995; for reviews, see Gallo 2006, 2010). Our findings confirm that distinctive encoding can improve correct memory while reducing false memory but also reveal that these benefits can come with costs. Moreover, we show that the pattern of costs/benefits depends on whether distinctive (vs. nondistinctive) encoding is varied within a group or between groups.

As reviewed by Hunt (2006), it seems intuitive that distinctive (vs. nondistinctive) encoding would require more attention and/or processing, suggestive of an encoding-based mechanism (Jenkins and Postman 1948; McDaniel and Geraci 2006). Indeed, an encoding locus for distinctiveness effects is 
supported by studies of divided attention at study, a manipulation that curtails participants' ability to engage in distinctive processing. Consistent with an encoding locus, dividing attention at study reduces the advantage for orthographically distinct (vs. regular) items in recall (Geraci and Rajaram 2002), and for low- (vs. high-) frequency words in recognition (Joordens and Hockley 2000).

Other evidence, however, suggests that distinctive encoding can benefit memory at retrieval. Von Restorff (1933) had participants study a list in which one item was isolated on a particular dimension, relative to others (e.g., a syllable within a list of digits). At test, recall was greater for the isolated item than for the nonisolated items. Importantly, this isolation effect occurred even when the isolate was presented at the start of the list before a context could have been established to contrast with the distinctive isolate (see also Dunlosky et al. 2000). Therefore, distinctiveness at encoding could not have produced this isolation benefit. Instead, the first-position isolate could be perceived as distinct only after the isolate was encoded, at which point the list context could be used during test to provide diagnostic evidence that the isolate was studied (Gallo 2004; Waddill and McDaniel 1998). This argument assumes that encoding of the isolate ends with the presentation of subsequent list items, but participants may return to rehearsing the isolate once the following items have established a context. This could result in the retrieval and preferential rehearsal of the isolate - to the detriment of other list items - suggesting that encoding might still contribute to distinctiveness effects. If so, whether the isolation effect reflects an encoding or a retrieval process becomes difficult to separate and resolve.

In addition to improving correct memory, distinctive encoding has also been shown to substantially reduce false memory in the DRM paradigm. In this paradigm, participants study several lists of related words (e.g., bed, rest, tired, etc.), each of which converges on a single nonstudied critical item (e.g., sleep). When tested, participants often recall and/or recognize the critical item as having been presented, resulting in a robust form of memory illusion. Researchers have subsequently explored various manipulations to reduce the DRM illusion, such as repeated study trials (Benjamin 2001; McDermott 1996), explicit warnings (Gallo et al. 2001; McCabe and Smith 2002), and-importantly for present purposesdistinctive encoding tasks (Arndt and Reder 2003; Dodson and Schacter 2001, 2002; Gunter et al. 2007; Huff and Bodner 2013; Israel and Schacter 1997; McCabe and Smith 2006). Distinctive encoding tasks may be particularly salutary because they can produce a mirror effect (Glanzer and Adams 1990) -increased correct memory coupled with decreased false memory-relative to a nondistinctive control condition (Gunter et al. 2007; Huff and Bodner 2013).

\section{Impoverished relational encoding versus the distinctiveness heuristic}

The DRM literature, too, has been rife with debate over whether the benefits of distinctive encoding arise at encoding or at retrieval. The impoverished relational encoding account (Arndt and Reder 2003; Hege and Dodson 2004; Hockley and Cristi 1996) posits that distinctive processing reduces semantic activation of the critical items by decreasing their associations to list items (Roediger et al. 2001) or by reducing the thematic consistency of the lists (Brainerd and Reyna 2002). In contrast, the distinctiveness heuristic account postulates that distinctive effects are due to the adoption of a global diagnostic monitoring strategy at test (Schacter et al. 2001; Schacter et al. 1999). In this account, recollection of distinctive details at test provides diagnostic evidence that an item was studied, and this absence is diagnostic evidence that an item (including a critical item) was not studied.

Several approaches have been used to try to separate encoding and retrieval loci for distinctiveness effects in the DRM paradigm. The most common approach has been to test a within-subjects condition: Half the DRM lists are studied using a distinctive encoding method and half using a control (e.g., read-only) task. To review one example, Schacter et al. (1999) had participants study half the DRM lists with a picture of each list word's referent provided and the other half without pictures. The DRM illusion was low and equivalent for both lists types, consistent with a retrieval-based distinctiveness heuristic (i.e., "if I can recall seeing the picture, the item is old; if not, it must be new"). Use of a global decision strategy increased monitoring and, thus, reduced false recognition of critical items from both distinctive and nondistinctive lists. In contrast, if the presentation of pictures at study had led to impoverished relational encoding, then the DRM illusion should have been selectively reduced for the distinctive (picture) lists. Although such results support the claim that distinctiveness benefits arise at retrieval, not all studies have found this pattern. For example, Arndt and Reder (2003) found a selective reduction in the DRM illusion for lists that were studied in distinctive (vs. nondistinctive) fonts, consistent with an encoding-based account.

Another approach to parsing out the contributions of encoding versus retrieval processes is through the use of an inclusion test (Brainerd et al. 2003; Gunter et al. 2007; Hege and Dodson 2004; Hunt et al. 2011). Under inclusion instructions, participants are asked to report or endorse all test items that were studied or are related to studied items. On this test, participants should therefore report or endorse the critical items, which presumably leads participants to abandon retrieval-based strategies such as the distinctiveness heuristic, that would otherwise operate to reduce the DRM illusion. As a result, any reduction of the DRM illusion due to distinctive encoding can be attributed to encoding-based processes. 
Similar to within-subjects tests, inclusion tests have yielded mixed findings. Distinctive encoding has sometimes reduced the DRM illusion, consistent with an encoding locus (e.g., Hege and Dodson 2004; Hunt et al. 2011), but other times has not, consistent with a retrieval locus (e.g., Gunter et al. 2007; Pierce et al. 2005; Schacter et al. 2001).

Most recently, we have advocated a signal detection approach for separating encoding and retrieval loci of distinctiveness effects in recognition (Gunter et al. 2007; Huff and Bodner 2013). Signal detection analyses attempt to partition participants' underlying memory experiences for studied versus nonstudied items from their response bias, or proclivity to report at test that an item was studied. The theory assumes that recognition experiences map onto a continuum of strength and that the distribution of experiences are typically further along this continuum for studied items than for nonstudied items. The distance between the standardized mean of these hit and false alarm distributions, $d^{\prime}$, provides an index of the amount of memory information that was encoded in a given condition (often termed sensitivity or discriminability; see MacMillan and Creelman 1991; Wickens 2002). Importantly, in the DRM paradigm, a $d^{\prime}$ index of memory information can also be calculated for false recognition of critical lures by calculating the standardized difference in recognition claims for critical items from studied lists (hits) minus nonstudied lists (false alarms). For false recognition, this analysis treats recognition claims for critical items from studied lists as hits and recognition claims for critical items from nonstudied lists as false alarms. A comparison of $d^{\prime}$ across distinctive and nondistinctive encoding conditions can thus be used to measure the encoding-based effects of distinctive encoding for both list items and critical items. For example, impoverished relational encoding should yield a smaller $d^{\prime}$ for critical items for distinctive (vs. nondistinctive) lists in a between design, whereas use of a distinctiveness heuristic should yield equivalent $d$ 's.

Signal detection theory can also be used to derive a suitable index of response bias (i.e., how liberally or conservatively participants respond during test). In the DRM paradigm, we have suggested that more conservative responding is indicative of an increase in test-based strategic memory monitoring, consistent with use of a distinctiveness heuristic (Gunter et al. 2007; Huff and Bodner 2013). Traditional measures of response bias, such as criterion $c$, are measured using a hit rate and a false alarm rate. However, such measures are not appropriate when evaluating the contributions of distinctive encoding that can produce a mirror effect (an increase in hits and a decrease in false alarms) by moving the hits and false alarm distributions in opposing directions. Given this divergence, bias measures should not be computed using both hits and false alarms.

A solution to this issue was provided by a helpful anonymous reviewer who recommended that we use an index of response criterion, lambda $(\lambda)$, which reflects the location of the nonstudied item distribution alone and, hence, is computed without recourse to a hit rate (see Wickens 2002). Lambda is computed as the $z$-score of 1 minus the false alarm rate. Higher $\lambda$ values reflect a more conservative response bias that we interpret as greater retrieval-based monitoring. As with $d^{\prime}, \lambda$ can also be computed for both list items (on the basis of false alarms to list item from nonstudied lists-i.e., list item controls) and critical items (on the basis of false alarms to critical items from nonstudied lists-i.e., critical item controls). A comparison of $\lambda$ across distinctive and nondistinctive encoding tasks can thus be used to gauge the retrievalbased effects of distinctive encoding for both list items and critical items. For example, use of a distinctiveness heuristic at test should yield larger $\lambda$ values, whereas impoverished relational encoding should not affect $\lambda$.

Huff and Bodner (2013) argued that the signal detection approach offers advantages over other approaches for separating encoding and retrieval processes. In brief, comparing false recognition for distinctive and nondistinctive lists in a within design relies upon a null effect of list type to infer the operation of a retrieval-based distinctiveness heuristic. In addition, this design assumes that encoding and retrieval processes are mutually exclusive; therefore, it is unable to detect situations in which processes operate in tandem. Inclusion tests are similarly plagued: A null effect is again used to indicate use of a retrieval-based distinctiveness heuristic. Conclusions based on these tests alone result in the affirmation of a disjunction in which finding evidence for one process eliminates the contribution of the other process by default.

Using the signal detection approach, Huff and Bodner (2013) separated the contributions of encoding and retrieval processes to correct and false recognition in the DRM paradigm, but only across between-group designs. Across experiments, they compared the effects of pleasantness ratings, anagram generation, and processing instructions with those of nondistinctive (read-only) control groups. Their signal detection indices revealed an interplay between encoding and retrieval processes in modulating correct and false recognition. For correct recognition, the indices of memory information $\left(d^{\prime}\right)$ and of memory monitoring $(\lambda)$ were both greater in the distinctive (vs. nondistinctive) groups, suggesting that the distinctiveness advantage was due to a combination of encoding and retrieval processes. For the DRM illusion, memory monitoring for critical items during test (i.e., the retrieval locus) was greater in the item-specific groups, but the effects on memory information (i.e., the encoding locus) differed across experiments. Specifically, memory information for critical items was lower following generation than following reading but was equivalent to reading following pleasantness ratings and item-specific instructions. Thus, distinctive encoding consistently increased retrieval-based 
monitoring, consistent with the distinctiveness heuristic account, but it led to impoverished relational encoding only following generation. ${ }^{1}$

\section{Distinctiveness effects in between versus within designs}

The benefits of distinctive encoding on correct recognition have been well characterized in between and within designs (Begg et al. 1989; Bertsch et al. 2007; McCabe and Smith 2006). In a between (pure list) design, distinctive encoding tasks presumably induce item-specific processing that helps individuate the list items. In a within (mixed list) design, distinctive list items can be further contrasted to nondistinctive list items that receive less item-specific processing. Because of this additional relative contrast, the benefits of distinctive encoding are often greater in a within design than in a between design (Bertsch et al. 2007; Fawcett 2013; McDaniel and Bugg 2008). Alternatively, Begg and Snider (1987) argued that the robust (distinctive) generation effect in a within design may sometimes be due to cursory processing of the (nondistinctive) read items, rather than to enhanced memory for the generate items. In other words, the apparent benefits of distinctive processing in a within design may actually reflect costs to nondistinctive items.

The costs and benefits of distinctive encoding in a within design can be gauged by comparing each type of item/list with its pure list counterpart (e.g., Begg and Snider 1987; Bodner, Taikh, and Fawcett 2014). A benefit occurs when memory for distinctively encoded items is greater in a within (vs. between) design. A cost occurs when memory for nondistinctively encoded items is lower in a within (vs. between) design. Using this analysis, Begg and Snider concluded that the within-subject generation effect in recognition largely reflects a cost to (nondistinctive) read items rather than a benefit to (distinctive) generate items. More recently, Bodner, Taikh, and Fawcett assessed the costs and benefits of the withinsubject production effect in recognition (i.e., an advantage for items studied aloud, as opposed to silently). The production effect is typically attributed to a benefit to aloud items resulting from increased distinctiveness (e.g., Bodner and Taikh 2012), yet their experiment and meta-analysis showed that, as with generation, the costs to silent (nondistinctive) items outweighed the benefits to aloud (distinctive) items.

An analysis of the costs/benefits of distinctiveness on both correct and false recognition in the DRM paradigm has never

\footnotetext{
${ }^{1}$ Gunter et al. (2007) reported that generation increased memory monitoring but did not decrease memory information encoded for critical items. However, in preparing our meta-analyses, we discovered an error in their data coding that led to an underestimation of the latter effect. In fact, generation reduced memory information encoded for critical items in their study, as in Huff and Bodner (2013). Table 1 provides the corrected means for Gunter et al.
}

been conducted, and remedying this situation was our second key goal. As was discussed above, false recognition in within groups is typically equivalent for distinctive and nondistinctive lists, and these null effects have been marshaled as evidence of a global monitoring strategy at test (McCabe and Smith 2006; Schacter et al. 1999; cf. Arndt and Reder 2003). But to establish that the DRM illusion has been reduced in a within group, each list type must be compared with a pure list counterpart - comparisons that have not been made to date. Thus, the pattern of results in the within design may reflect benefits, costs, or a combination of the two. Here, benefits refer to a decrease in false recognition for critical items from nondistinctive (i.e., read) lists in the within group, relative to a pure-list read group. Costs refer to an increase in false recognition for critical items from distinctive lists in the within group, relative to a pure distinctive-list group.

Measuring the costs and benefits of distinctive processing in within (vs. between) designs is important because it can specify how distinctive encoding affects both correct memory and memory errors. Dodson and Schacter (2002) suggested that "there is no cost to using the distinctiveness heuristic" (p. 798) in the DRM paradigm, but they did not report comparisons across within and between designs to substantiate this claim. Our analyses determined whether distinctive encoding is truly "cost free" or might, for example, impair memory for nondistinctively encoded items. This is important in terms of recommending distinctiveness as a general strategy for memory improvement.

\section{Meta-analyses}

We conducted a series of meta-analyses to accomplish two goals. First, we used signal detection indices to further evaluate Huff and Bodner's (2013) claim that reductions in the DRM illusion due to distinctive encoding are driven by both encoding (impoverished relational encoding) and retrieval (distinctiveness heuristic) mechanisms. Second, we examined whether distinctive encoding exclusively produces benefits (i.e., a "cost free" strategy; Dodson and Schacter 2002) or might produce costs to nondistinctive items, as found in other domains (e.g., Begg and Snider 1987; Bodner, Huff et al. 2014). Furthermore, we evaluated how the effects of distinctive encoding are modulated by the use of a within (vs. between) design. That is, does the presence of nondistinctive lists in a within design affect the encoding and/or retrieval of the distinctive lists? In sum, we determined the costs and benefits of distinctive processing in each design, as well as their loci.

To accomplish these objectives, we searched for DRM recognition studies in which distinctive versus nondistinctive (i.e., read-only control) encoding tasks were manipulated across between and within designs in the same study (although usually across experiments). We searched for suitable studies via Web 
of Science, PsycInfo, and Google searches. Available authors of included studies were also emailed for other leads and suitable unpublished data sets. Distinctive encoding was operationalized as a task designed to improve memory for studied items and/or to decrease the DRM illusion. Studies that did not meet these requirements were excluded. Of the nine data sets we obtained that met these criteria, five used generation as the distinctive encoding condition:

1. Bodner, Huff, Gunter, and Azad (2014, unpublished raw data);

2. Gunter (2004, unpublished Master's thesis);

3. Gunter et al. (2007, Experiment 1A vs. 2A);

4. Huff and Bodner (2014, unpublished raw data);

5. McCabe and Smith (2006, Experiment 1 vs. 2);

Three more studies presented pictures along with list words in the distinctive conditions:

6. Schacter et al. (1999, Experiment 1 vs. 2; younger adults);

7. Schacter et al. (1999, Experiment 1 vs. 2, older adults);

8. Schacter et al. (2001; Experiment 1).

The final study used production (i.e., saying list words aloud) in the distinctive conditions:

\section{Dodson and Schacter (2001; Experiments 1 vs. 2). ${ }^{2}$}

Discriminability $\left(d^{\prime}\right)$, an index of encoded memory information, and lambda $(\lambda)$, an index of memory monitoring at test, were calculated from raw participant means, with the exception of McCabe and Smith (2006) and Schacter et al. (1999), for which the published group means and standard deviations were imputed from the weighted average of the other studies. Table 1 reports the mean indices for the distinctive and nondistinctive conditions in each study (Table 2 provides the mean hit and false alarm rates). The mean $d^{\prime}$ and $\lambda$ scores were then used to calculate standardized mean difference scores for each of the comparisons described below. For between-group comparisons, these scores were calculated using the escalc function from the metafor package (Viechtbauer 2010) within $\mathrm{R}$ version 3.0.1 (R Development Core Team 2013). This function produces an

\footnotetext{
${ }^{2}$ Arndt and Reder (2003) manipulated distinctive versus nondistinctive fonts across between and within designs in the DRM paradigm. This study was initially included in our meta-analyses, but it was often identified as an outlier by visual inspection and regression-deletion diagnostics (e.g., Cook's distance, studentized deleted residual). Calculation of the covariance ratio further suggested that its inclusion substantially reduced the precision of our estimated effects. Therefore, this study was included in the tables and meta-analysis figures for comparison purposes but was eliminated from the summary effects in the meta-analyses. The possibility that font (a stimulus-based, perceptual manipulation) might differ in the basis of its effect from other distinctiveness tasks (processingbased, conceptual manipulations) warrants further exploration.
}

estimate of Hedges's $g$ (Hedges 1981) corrected for its slight positive bias (Hedges and Olkin 1985). For within-group comparisons, comparable scores were calculated using the equations recommended by Borenstein (2009) to account for the dependence among the included means. The correlations necessary for these comparisons were calculated from the raw data where possible; for studies where this information was unavailable (McCabe and Smith 2002; Schacter et al. 1999), suitable correlations were imputed, instead, from the weighted average of the other studies (see, e.g., Higgins and Green 2009; Pigott 2009). ${ }^{3}$

Following calculation of the effect sizes, a series of random-effects models were fitted to the aggregate data to estimate an overall effect for each comparison. All models were generated using the rma function from the metafor package in R (see Viechtbauer 2010). Although efforts were taken to avoid publication bias, trim and fill analyses (Duval 2005) were also conducted for each random-effects model. These models evaluate evidence for publication bias favoring the inclusion of small studies with large, statistically significant effect sizes, rather than small studies with small, statistically nonsignificant effect sizes. In the event that evidence exists for such a bias, the missing nonsupportive studies are imputed, and the model is reconducted to test the sensitivity of our analyses to those missing studies. Although typically used to gauge evidence for missing nonsupportive studies, we also evaluated evidence of missing supportive studies in the same manner. Except where specifically noted, the trim and fill analyses found no evidence of missing studies; thus, the resulting model did not differ from the reported models.

\section{Confirming the effects of distinctiveness}

The first pair of meta-analyses (Fig. 1) sought to confirm the benefits of distinctive (vs. nondistinctive) encoding in the within-group "tests." For studied list items, more memory information $\left(d^{\prime}\right)$ was encoded for distinctive (vs. nondistinctive) lists $\left(g=0.79, \mathrm{CI}_{95 \%}=0.46,1.11 ; Q(8)=53.07, p<.001\right.$; $I^{2}=87.84 \%$; Fig. 1 , top). Importantly, there was no difference in encoded memory information $\left(d^{\prime}\right)$ for critical lures from distinctive versus nondistinctive lists $\left(g=0.10, \mathrm{CI}_{95 \%}=\right.$ $-0.04,0.23 ; Q(8)=7.09, p=.527 ; I^{2}<0.01 \%$; Fig. 1 , bottom). The latter result confirms the distinctiveness pattern in which false recognition of critical items is equivalent for both list types in within-subjects groups. ${ }^{4}$

Inspection of Fig. 1 suggests that the presence of substantial heterogeneity in our analysis of memory information for studied list items was moderated by the type of distinctive

\footnotetext{
${ }_{3}^{3}$ Sensitivity analyses carried out on these and other imputations reported verify that our findings are robust across the range of possible values observed for each variable.

${ }^{4}$ Meta-analyses of memory monitoring across distinctive and nondistinctive lists in the within groups was not possible, because critical item controls do not belong to either distinctive or nondistinctive lists.
} 
Table 1 Mean signal detection indices of encoded memory information $\left(d^{\prime}\right)$ and memory monitoring at test $(\lambda)$ for between and within designs and for distinctive (D) and nondistinctive (ND) lists, and effects of design by list type and list type by design used in the meta-analyses

\begin{tabular}{|c|c|c|c|c|c|c|c|c|}
\hline \multirow[b]{3}{*}{ Task/Study/Means } & \multirow{2}{*}{\multicolumn{2}{|c|}{ Between (B) }} & & & \multirow{2}{*}{\multicolumn{2}{|c|}{$\frac{\text { Design Effect }}{(B-W)}$}} & \multirow{2}{*}{\multicolumn{2}{|c|}{$\frac{\text { List Effect }}{\text { (Dlists - NDlists) }}$}} \\
\hline & & & \multicolumn{2}{|c|}{ Within (W) } & & & & \\
\hline & Dlists & NDlists & Dlists & NDlists & Dlists & NDlists & Between & Within \\
\hline \multicolumn{9}{|l|}{ Generation } \\
\hline \multicolumn{9}{|c|}{ Bodner, Huff, Gunter, \& Azad (2014) } \\
\hline List item $d^{\prime}$ & 2.56 & 1.13 & 2.65 & 1.92 & -0.09 & 0.21 & 0.43 & 0.73 \\
\hline List item $\lambda$ & 1.47 & 1.34 & 1.37 & 0.10 & -0.03 & 0.13 & & \\
\hline Critical item $d^{\prime}$ & 1.17 & 1.87 & 1.28 & 1.10 & -0.11 & 0.77 & -0.70 & 0.18 \\
\hline Critical item $\lambda$ & 1.18 & 1.06 & 1.11 & 0.07 & -0.05 & 0.12 & & \\
\hline \multicolumn{9}{|l|}{ Gunter (2004) } \\
\hline List item $d^{\prime}$ & 2.92 & 1.77 & 2.69 & 1.85 & 0.23 & -0.08 & 1.15 & 0.84 \\
\hline List item $\lambda$ & 1.49 & 0.90 & 1.22 & 0.27 & -0.32 & 0.59 & & \\
\hline Critical item $d^{\prime}$ & 0.93 & 1.27 & 1.10 & 0.85 & -0.18 & 0.42 & -0.34 & -0.59 \\
\hline Critical item $\lambda$ & 1.09 & 0.54 & 0.79 & 0.30 & -0.25 & 0.55 & & \\
\hline \multicolumn{9}{|c|}{ Gunter, Bodner, \& Azad (2007) } \\
\hline List item $d^{\prime}$ & 2.76 & 2.21 & 2.81 & 1.91 & -0.05 & 0.30 & 0.55 & 0.90 \\
\hline List item $\lambda$ & 1.62 & 1.32 & 1.27 & 0.35 & 0.05 & 0.30 & & \\
\hline Critical item $d^{\prime a}$ & 1.09 & 1.43 & 1.10 & 0.93 & -0.01 & 0.50 & -0.34 & 0.17 \\
\hline Critical item $\lambda$ & 1.26 & 0.91 & 0.96 & 0.30 & -0.05 & 0.36 & & \\
\hline \multicolumn{9}{|c|}{ Huff and Bodner (2014) } \\
\hline List item $d^{\prime}$ & 2.73 & 2.11 & 2.61 & 1.53 & 0.12 & 0.58 & 0.62 & 1.08 \\
\hline List item $\lambda$ & 1.67 & 1.36 & 1.26 & 0.41 & 0.10 & 0.31 & & \\
\hline Critical item $d^{\prime}$ & 1.03 & 1.39 & 1.42 & 0.89 & -0.39 & 0.41 & -0.36 & 0.44 \\
\hline Critical item $\lambda$ & 1.34 & 1.02 & 1.11 & 0.23 & -0.09 & 0.32 & & \\
\hline \multicolumn{9}{|c|}{ McCabe and Smith (2006) } \\
\hline List item $d^{\prime}$ & 2.62 & 2.27 & 2.32 & 1.89 & 0.30 & 0.38 & 0.35 & 0.43 \\
\hline List item $\lambda$ & 1.13 & 1.13 & 0.95 & 0.18 & -0.18 & 0.00 & & \\
\hline Critical item $d^{\prime}$ & 1.35 & 2.01 & 1.99 & 2.05 & -0.64 & -0.04 & -0.66 & -0.06 \\
\hline Critical item $\lambda$ & 0.84 & 0.92 & 0.81 & 0.03 & 0.11 & -0.08 & & \\
\hline \multicolumn{9}{|l|}{ Pictures } \\
\hline \multicolumn{9}{|c|}{ Schacter, Israel, \& Racine (1999; younger adult group) ${ }^{*}$} \\
\hline List item $d^{\prime}$ & 2.11 & 1.61 & 1.91 & 1.63 & 0.20 & -0.02 & 0.50 & 0.28 \\
\hline List item $\lambda$ & 1.34 & 0.81 & 0.95 & 0.39 & -0.14 & 0.53 & & \\
\hline Critical item $d^{\prime}$ & 1.02 & 1.00 & 0.60 & 0.65 & 0.42 & 0.35 & 0.02 & -0.05 \\
\hline Critical item $\lambda$ & 1.41 & 0.58 & 0.67 & 0.74 & -0.13 & 0.83 & & \\
\hline \multicolumn{9}{|c|}{ Schacter et al. (1999; older adult group)* } \\
\hline List item $d^{\prime}$ & 1.96 & 1.17 & 1.51 & 1.03 & 0.45 & 0.14 & 0.79 & 0.48 \\
\hline List item $\lambda$ & 1.14 & 0.58 & 0.77 & 0.64 & -0.19 & 0.83 & & \\
\hline Critical item $d^{\prime}$ & 0.89 & 1.54 & 0.98 & 1.06 & -0.09 & 0.48 & -0.65 & -0.08 \\
\hline Critical item $\lambda$ & 0.99 & 0.95 & 0.64 & 0.35 & 0.31 & 0.04 & & \\
\hline \multicolumn{9}{|c|}{ Schacter, Cendan, Dodson, \& Clifford (2001) } \\
\hline List item $d^{\prime}$ & 1.99 & 1.68 & 2.11 & 1.88 & -0.12 & -0.20 & 0.31 & 0.33 \\
\hline List item $\lambda$ & 1.60 & 1.21 & 1.50 & 0.10 & -0.29 & 0.39 & & \\
\hline Critical item $d^{\prime}$ & 0.65 & 1.12 & 0.66 & 0.66 & -0.01 & 0.46 & -0.46 & 0.00 \\
\hline Critical item $\lambda$ & 1.38 & 0.94 & 1.09 & 0.19 & -0.15 & 0.44 & & \\
\hline \multicolumn{9}{|l|}{ Production } \\
\hline \multicolumn{9}{|c|}{ Dodson and Schacter (2001) } \\
\hline List item $d^{\prime}$ & 1.99 & 1.75 & 2.27 & 1.99 & -0.28 & -0.24 & 0.24 & 0.28 \\
\hline
\end{tabular}


Table 1 (continued)

\begin{tabular}{|c|c|c|c|c|c|c|c|c|}
\hline \multirow[b]{3}{*}{ Task/Study/Means } & & & & & Design & & List Effec & \\
\hline & \multicolumn{2}{|c|}{ Between (B) } & \multicolumn{2}{|c|}{ Within (W) } & \multicolumn{2}{|c|}{$(\mathrm{B}-\mathrm{W})$} & \multicolumn{2}{|c|}{ (Dlists - NDlists) } \\
\hline & Dlists & NDlists & Dlists & NDlists & Dlists & NDlists & Between & Within \\
\hline List item $\lambda$ & 1.22 & 1.15 & 1.38 & -0.16 & -0.23 & 0.07 & & \\
\hline Critical item $d^{\prime}$ & 0.73 & 1.38 & 1.34 & 1.31 & -0.61 & 0.07 & -0.65 & 0.03 \\
\hline Critical item $\lambda$ & 0.65 & 0.64 & 1.09 & -0.44 & -0.45 & 0.01 & & \\
\hline \multicolumn{9}{|l|}{ Font } \\
\hline \multicolumn{9}{|c|}{ Arndt and Reder $(2003)^{\mathrm{c}}$} \\
\hline List item $d^{\prime}$ & 2.49 & 2.78 & 2.67 & 2.76 & -0.18 & 0.02 & -0.29 & -0.09 \\
\hline List item $\lambda$ & 1.27 & 1.43 & 1.18 & 0.09 & 0.25 & -0.16 & & \\
\hline Critical item $d^{\prime}$ & 0.88 & 1.83 & 1.07 & 1.72 & -0.19 & 0.11 & -0.95 & -0.65 \\
\hline Critical item $\lambda$ & 0.96 & 1.00 & 0.87 & 0.09 & 0.13 & -0.04 & & \\
\hline \multicolumn{9}{|c|}{ Average (excluding Arndt and Reder 2003) } \\
\hline List item $d^{\prime}$ & 2.40 & 1.86 & 2.32 & 1.74 & 0.08 & 0.12 & 0.55 & 0.58 \\
\hline List item $\lambda$ & 1.44 & 1.09 & 1.19 & 0.25 & -0.10 & 0.35 & & \\
\hline Critical item $d^{\prime}$ & 0.98 & 1.45 & 1.16 & 1.07 & -0.18 & 0.38 & -0.46 & 0.10 \\
\hline Critical item $\lambda$ & 1.13 & 0.84 & 0.92 & 0.21 & -0.08 & 0.29 & & \\
\hline
\end{tabular}

Note. Bolded means correspond to effect sizes calculated in the meta-analyses. MD = mean difference as represented in the table.

* Signal detection indices were computed from published group means.

${ }^{a}$ Means reported in the original article were incorrect.

${ }^{\mathrm{b}}$ Dlists collapsed across generation and self-imagery tasks.

${ }^{\mathrm{c}}$ Dlists collapsed across the uncorrelated and unique font groups, NDlists is the correlated font group.

encoding task. We therefore fit an exploratory mixed-effects model comparing data from generation tasks with the combination of all other distinctive tasks. This comparison was significant in a meta-regression model $\left(B=0.64, \mathrm{CI}_{95 \%}=\right.$ $0.13,1.16$ ), explaining $43.78 \%$ of the heterogeneity in our earlier model of these effects. The benefits were larger for generation $\left(g=1.07, \mathrm{CI}_{95 \%}=0.72,1.43\right)$ than for the other distinctive tasks $\left(g=0.43, \mathrm{CI}_{95 \%}=0.06,0.80\right)$.

Do distinctiveness effects arise at encoding and/or retrieval?

The second pair of meta-analyses (Fig. 2) focused on correct recognition in the between-groups design and tested whether distinctive (vs. nondistinctive) encoding increases memory information and/or memory monitoring at test $(\lambda)$ for list items. Distinctive (vs. nondistinctive) encoding increased encoded memory information $\left(d^{\prime} ; g=0.82, \mathrm{CI}_{95 \%}=0.56\right.$, $1.07 ; Q(8)=13.75, p=.089 ; I^{2}=40.56 \%$; Fig. 2 , top) and also increased memory monitoring at test $\left(\lambda ; g=0.61, \mathrm{CI}_{95 \%}=\right.$ $0.32,0.91 ; Q(8)=18.18, p=.019 ; I^{2}=57.06 \%$; Fig. 2, bottom), replicating Huff and Bodner (2013). In the latter case, a trim-and-fill analysis revealed evidence of one missing study; however, imputing this missing study did not affect our conclusions $\left(g=0.53, \mathrm{CI}_{95 \%}=0.20,0.86 ; Q(9)=25.54\right.$, $\left.p=.019 ; I^{2}=67.69 \%\right)$. Thus, both encoding and retrieval processes facilitate recognition of list items following distinctive encoding.

The third pair of meta-analyses (Fig. 3) were analogous, but focused on false recognition of critical items. The pattern here also replicated Huff and Bodner (2013): Distinctive groups encoded less memory information for critical items $\left(d^{\prime} ; g=-0.57, \mathrm{CI}_{95 \%}=-0.78,-0.35 ; Q(8)=10.01, p=.265\right.$; $I^{2}=22.49 \%$; Fig. 3 , top) and also performed more memory monitoring for critical items at test $\left(\lambda ; g=0.53, \mathrm{CI}_{95 \%}=0.19\right.$, 0.86; $Q(8)=23.29, p=.003 ; I^{2}=67.47 \%$; Fig. 3, bottom). These results provide compelling evidence that both encoding and retrieval factors shape distinctiveness benefits. Overall, the distinctive (vs. nondistinctive) groups encoded more information about list items and less information about critical items (consistent with an impoverished relational encoding account) and also performed more memory monitoring at test (consistent with a distinctiveness heuristic at test). Together, these influences induced a mirror effect: improved recognition of list items and reduced recognition of critical items.

Do distinctiveness manipulations produce benefits and/or costs?

The fourth pair of meta-analyses (Fig. 4) evaluated whether the within (vs. between) groups showed improved recognition 


\section{Memory information ( $\left.d^{\prime}\right)$ for list items in within-group designs: $D_{\text {lists }}-N D_{\text {lists }}$}

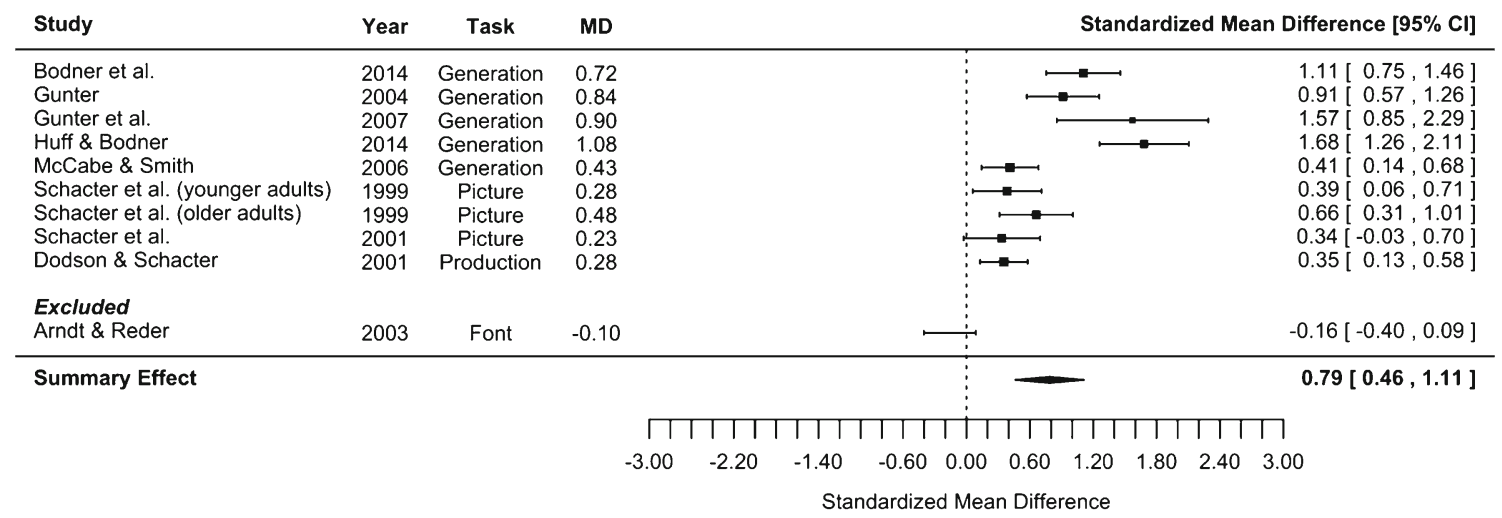

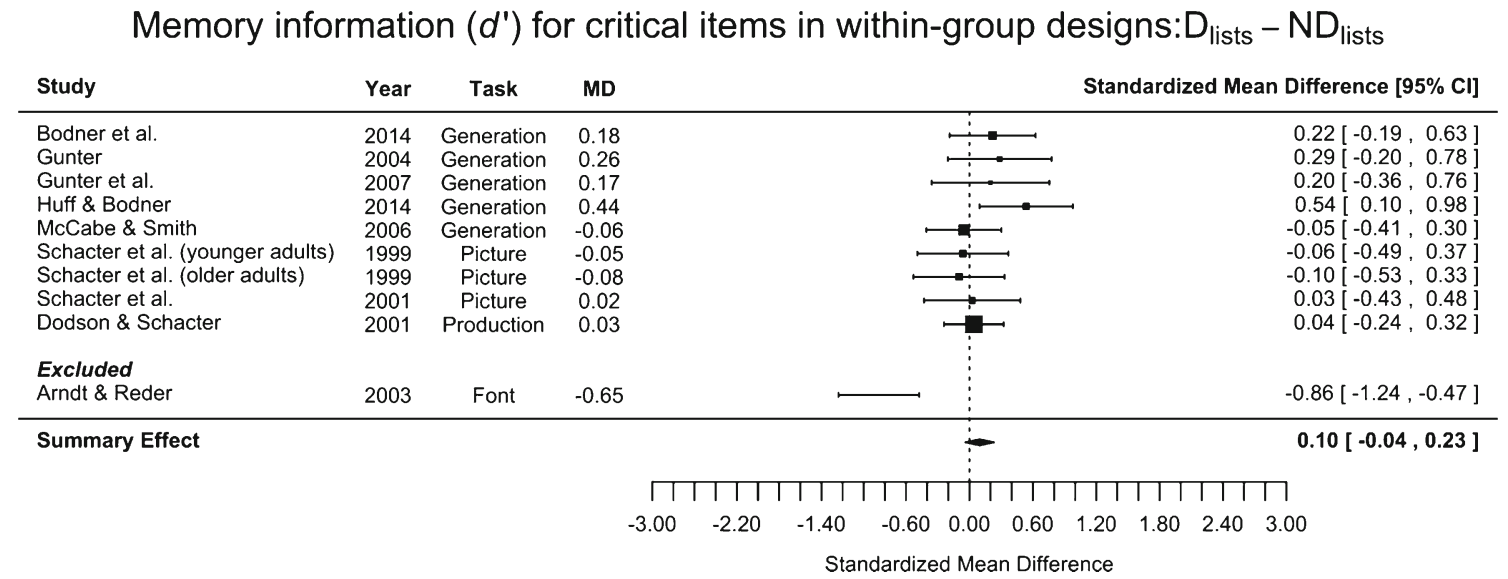

Fig. 1 Meta-analyses of the influence of distinctive encoding on memory information for list items (top) and critical items (bottom) in withinsubjects designs. Effect sizes and confidence intervals are based on standardized mean differences in a given index. The polygon at the bottom of each panel represents the summary effect for each analysis calculated using a random-effects model, excluding Arndt and Reder (2003; see Footnote 2). The square marker size indicates weight within the model. Dlists = distinctive lists; NDlists = nondistinctive lists. $\mathrm{MD}=$ mean difference as represented in Table 1 of distinctive list items and/or impaired recognition of nondistinctive list items. To gauge benefits, the $d$ 's for distinctive lists were compared across between and within groups. To gauge costs, the $d$ 's for nondistinctive lists were compared across the between and within groups. Recognition of distinctive list items was not improved in the within groups $(g=0.10$, $\mathrm{CI}_{95 \%}=-0.10,0.29 ; Q(8)=9.09, p=.335 ; I^{2}=8.68 \%$ Fig. 4, top), nor was recognition of nondistinctive list items impaired in the within groups $\left(g=0.21, \mathrm{CI}_{95 \%}=-0.05,0.46\right.$; $Q(8)=15.21, p=.055 ; I^{2}=47.57 \%$ Fig. 4 , bottom). In the latter case, a trim-and-fill analysis revealed evidence of one missing study that was supportive of the effect; in this case, imputing this missing study would result in a significant effect $\left(g=0.27, \mathrm{CI}_{95 \%}=0.001,0.53 ; Q(9)=19.46, p=.022 ; I^{2}=\right.$ $54.18 \%$ ). Thus, distinctive encoding yielded neither benefits nor costs to correct recognition, contrary to prior demonstrations of costs to nondistinctive items (Begg and Snider 1987; Bodner, Taikh and Fawcett 2014).
However, an exploratory analysis revealed that the type of distinctive encoding task moderated costs. We fit a mixedeffects model comparing data from generation tasks with the combination of all other distinctive tasks. In the generation studies, recognition of nondistinctive list items suffered a cost in a within design $\left(g=0.42, \mathrm{CI}_{95 \%}=0.17,0.67\right.$; Fig. 4, bottom). In contrast, there was no such cost to list item recognition for the other distinctive tasks $\left(d^{\prime} ; g=-0.11\right.$, $\left.\mathrm{CI}_{95 \%}=-0.43,0.21\right)$. This difference was significant in a meta-regression model $\left(B=0.53, \mathrm{CI}_{95 \%}=0.12,0.94\right)$, explaining $87.08 \%$ of the heterogeneity in that model.

The final pair of meta-analyses (Fig. 5) evaluated the costs/ benefits of distinctive encoding for false recognition of critical items. Interestingly, false recognition of critical items from distinctive lists was higher in a within (vs. between) design $\left(g=-0.19, \mathrm{CI}_{95 \%}=-0.38,0.00, p<.05 ; Q(8)=8.85\right.$, $p=.355 ; I^{2}=0.26 \%$; Fig. 5 , top), showing a novel distinctiveness cost. Moreover, false recognition of critical items 
Memory information $\left(d^{\prime}\right)$ for list items in between-group designs: $D_{\text {lists }}-N D_{\text {lists }}$

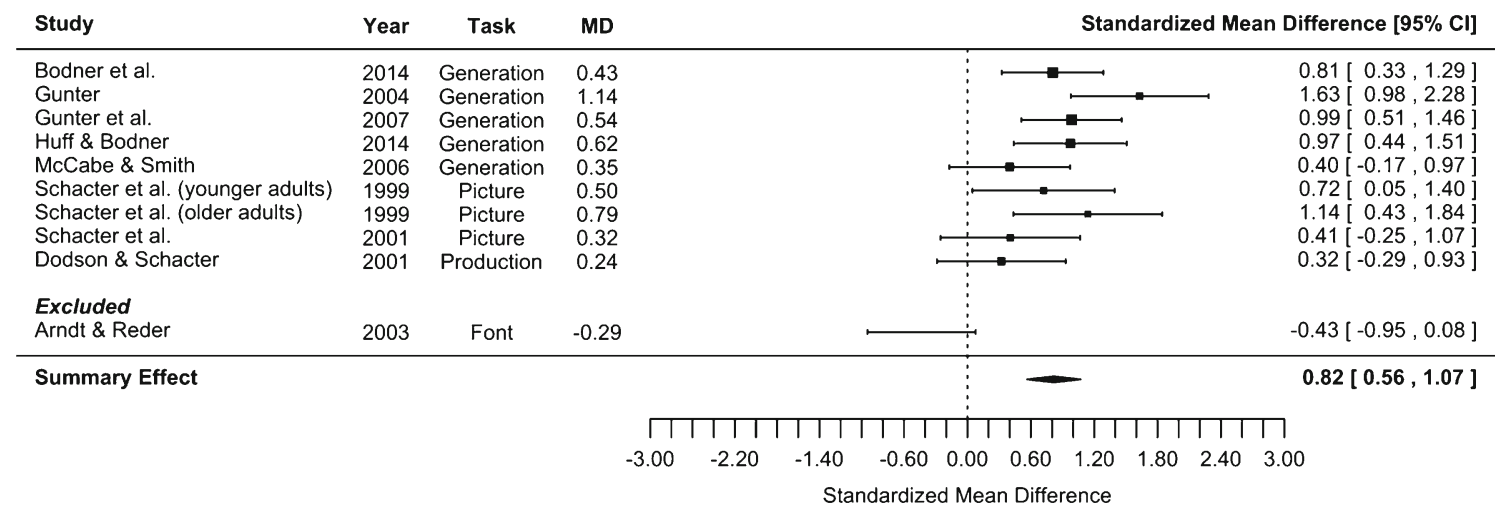

Memory monitoring $(\lambda)$ for list items in between-group designs: $D_{\text {lists }}-N D_{\text {lists }}$

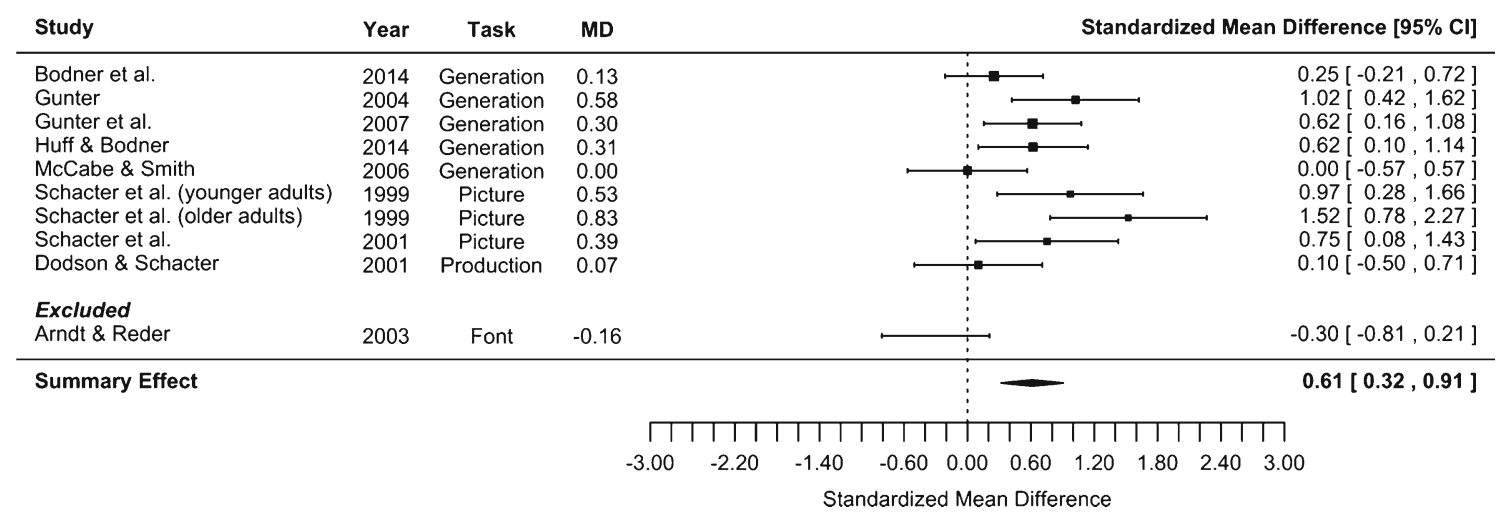

Fig. 2 Meta-analyses of the influence of distinctive encoding on memory information (top) and memory monitoring at test (bottom) for list items in between-group designs. Effect sizes and confidence intervals are based on standardized mean differences in a given index. The polygon at the bottom of each panel represents the summary effect for each analysis calculated using a random-effects model, excluding Arndt and Reder (2003; see Footnote 2). The square marker size indicates weight within the model. Dlists $=$ distinctive lists; NDlists $=$ nondistinctive lists. $\mathrm{MD}=$ mean difference as represented in Table 1 from nondistinctive lists was lower in a within (vs. between) design $\left(d^{\prime} ; g=0.50, \mathrm{CI}_{95 \%}=0.25,0.75 ; Q(8)=13.79\right.$, $p=.087 ; I^{2}=43.10 \%$; Fig. 5 , bottom), showing a novel nondistinctiveness benefit. In this case, both analyses revealed evidence of two missing studies; in the former case, these missing studies were supportive of the effect, whereas in the latter case, they were nonsupportive; however, our conclusions remain unaffected for either the distinctiveness cost $(g=$ $-0.29, \mathrm{CI}_{95 \%}=-0.50,-0.08 ; Q(10)=16.13, p=.096 ; I^{2}=$ $35.89 \%)$ or the nondistinctiveness benefit $\left(g=0.38, \mathrm{CI}_{95 \%}=\right.$ $\left.0.12,0.64 ; Q(10)=23.58, p=.009 ; I^{2}=56.65 \%\right)$. Thus, on the one hand, a within design was less effective at reducing false recognition of distinctive critical items (i.e., it made the distinctive encoding task less effective - a cost), and on the other hand, it also reduced false recognition of critical items from nondistinctive lists (a benefit). Phrased differently, a within design is worse at reducing false recognition for distinctive lists but is better at reducing false recognition for nondistinctive lists.

\section{Discussion}

The present review and meta-analyses helps bring clarity to the effects of distinctive encoding on recognition in the DRM paradigm and on the mechanisms that produce them. We examined whether distinctive encoding tasks improve correct recognition by facilitating encoding (amount of encoding memory information), retrieval (amount of memory monitoring at test), or both. Using signal detection estimates of each locus, the benefits of distinctive encoding of all DRM lists (i.e., in a between design) were shown to arise at both loci, as evidenced by increased $d^{\prime}$ and $\lambda$, respectively. Similarly, the benefits of distinctive processing on false recognition of critical items reflected a bifurcated pattern: a reduction in $d^{\prime}$ and an increase in $\lambda$. In other words, distinctive encoding tasks promote item-specific processing (and/or impair relational encoding) and also promote greater memory monitoring at test (i.e., a distinctiveness heuristic) in the DRM paradigm. Thus, our findings confirm that the two mechanisms are 
Memory information $\left(d^{\prime}\right)$ for critical items in between-group designs: $D_{\text {lists }}-N D_{\text {lists }}$

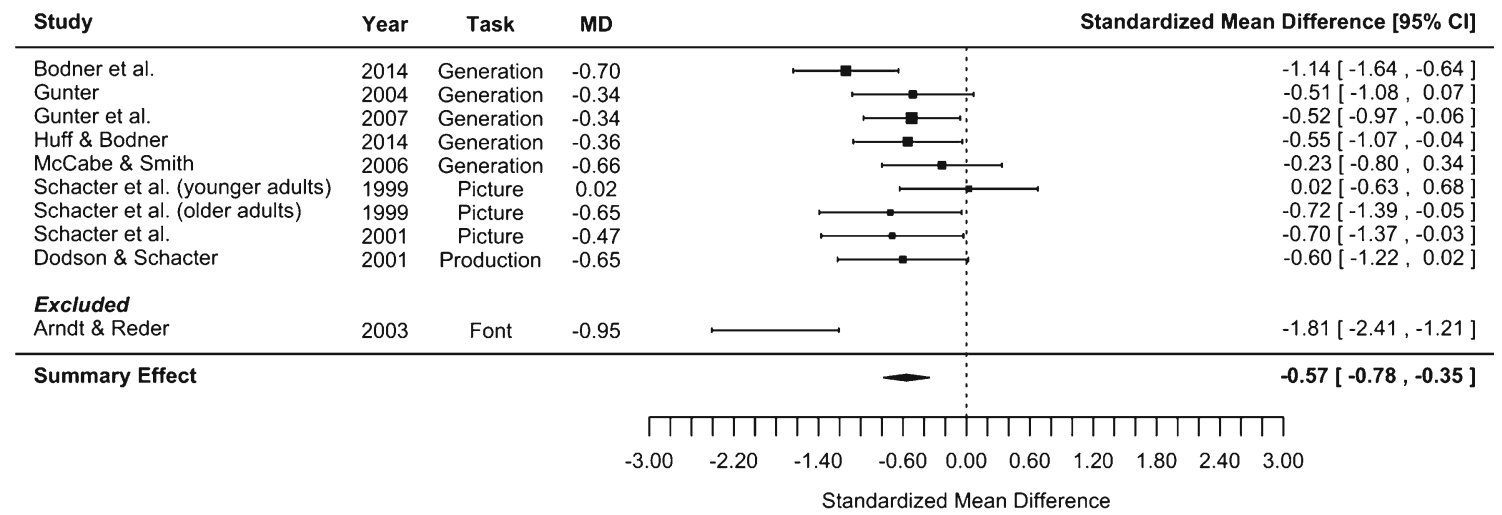

Memory monitoring $(\lambda)$ for critical items in between-group designs: $D_{\text {lists }}-N D_{\text {lists }}$

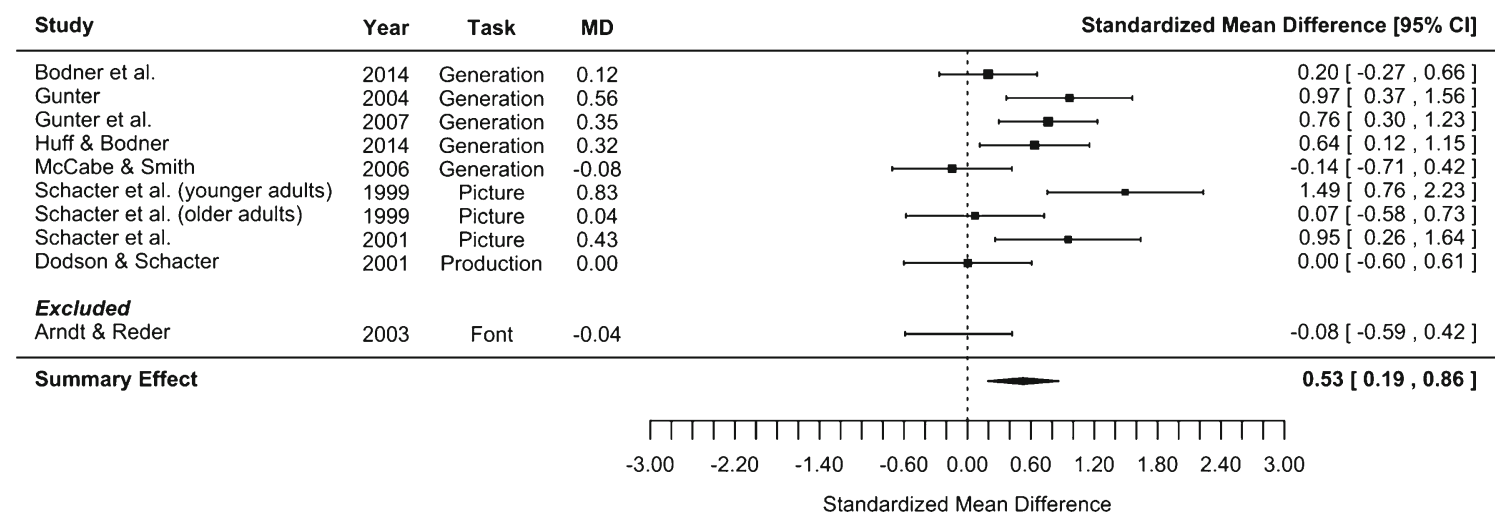

Fig. 3 Meta-analyses of the influence of distinctive encoding on memory information (top) and memory monitoring at test (bottom) for critical items in between-group designs. Effect sizes and confidence intervals are based on standardized mean differences in a given index. The polygon at the bottom of each panel represents the summary effect for each analysis calculated using a random-effects model, excluding Arndt and Reder (2003; see Footnote 2). The square marker size indicates weight within the model. Dlists $=$ distinctive lists; NDlists $=$ nondistinctive lists. $\mathrm{MD}=$ mean difference as represented in Table 1 complementary rather than mutually exclusive (Huff and Bodner 2013).

We also evaluated whether the benefits of distinctive encoding in within designs reflect benefits and/or costs, by comparing each list type in the within design with its between group counterpart. For correct recognition, both types of list items yielded similar $d$ 's across the two designs. However, when generation was the distinctive encoding task, we found that recognition of nondistinctively encoded list items suffered a cost in a within (vs. between) design, a pattern consistent with findings outside the DRM paradigm (e.g., Begg and Snider 1987; Bodner, Taikh and Fawcett 2014). This pattern raises the possibility that after encoding a generate list, participants engage in somewhat "lazier" encoding of a read list, as Begg and colleagues found for intermixed read and generate trials. If so, one peril of performing distinctive encoding for some lists is that it can lead to shallower encoding of nondistinctive lists. Whether this recognition trade-off is a pro or a con depends on the learner's goals (see Bodner, Taikh and
Fawcett 2014, for a discussion). If a learner's goal is to increase correct recognition for a subset of studied items, distinctive processing of that subset of items will be effective. In other words, the cost/benefit trade-off is specific to a within-subjects design. However, if the learner wishes to improve recognition of all studied items, it may be better to engage in distinctive processing of all items.

For false recognition, distinctive encoding in a within design yielded both a cost and a benefit. The cost was that participants encoded more information about the critical items for the distinctively encoded lists. Thus, distinctive encoding was less effective at reducing the DRM illusion in a within design. Alternating encoding task type across lists may render the distinctive encoding task less effective; it may be worth exploring whether blocking distinctive and nondistinctive lists reduces this cost. The benefit was that participants encoded less information about the critical items for nondistinctively encoded lists in a within (vs. between) design. Performing distinctive encoding for some lists might have a carryover 
Memory information $\left(d^{\prime}\right)$ for list items from distinctive lists: Between - Within

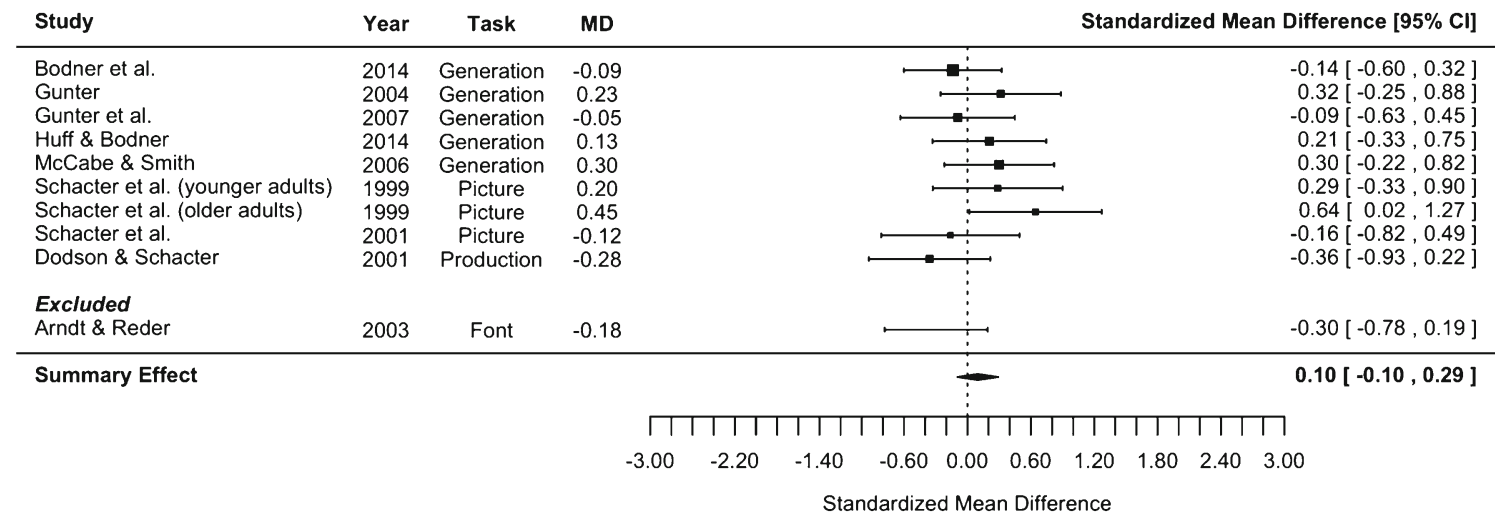

Memory information $\left(d^{\prime}\right)$ for list items from nondistinctive lists: Between - Within

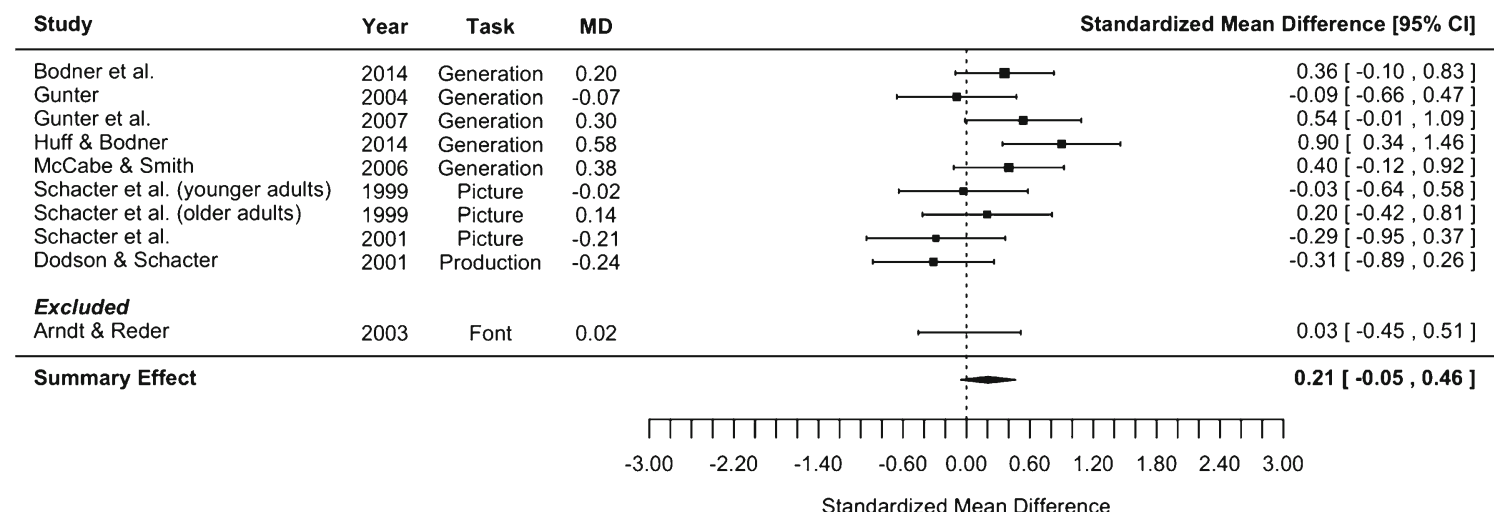

Fig. 4 Meta-analyses of the influence of design on memory information for list items from distinctive lists (Dlists; top) and nondistinctive lists (NDlists; bottom). Effect sizes and confidence intervals are based on standardized mean differences in a given index. The polygon at the

effect, either increasing item-specific encoding and/or decreasing relational encoding of nondistinctive lists (see Huff and Bodner 2013).

Potential limitations of the meta-analyses

We believe there is merit to conducting meta-analyses even for small sets of studies to help bring resolution to existing debates (e.g., impoverished relational encoding vs. distinctiveness heuristic) and to reveal previously undetected effects (e.g., costs of distinctive encoding; see also Fawcett 2013). Of course, meta-analysis can also yield misleading effect size estimates, resulting in incorrect conclusions. We attempted to avoid the potential pitfalls of meta-analyses outlined by Rosenthal and Dimatteo (2002).

First, we tried to avoid a publication bias by seeking and including unpublished data sets and by examining funnel plots for the presence of bias. These plots were not suggestive of publication bias - a fact also supported by our trim-and-fill analyses. bottom of each panel represents the summary effect for each analysis, calculated using a random-effects model, excluding Arndt and Reder (2003; see Footnote 2). The square marker size indicates weight within the model. $\mathrm{MD}=$ mean difference as represented in Table 1

Second, the apples-to-oranges problem involves comparing data sets that used dissimilar independent and dependent variables. We avoided this pitfall by using only encoding tasks identified as "distinctive" in the literature and by analyzing means based on a single memory test (i.e., recognition). For this reason, we opted not to include studies that included betweengroup conditions but no within condition (e.g., Huff and Bodner 2013) when computing the between-group meta-analyses.

Third, nonindependence occurs when multiple data sets are taken from the same study. In our meta-analyses, this was true for two of our data sets (Schacter et al. 1999), but distinguishing them (rather than averaging them) proved important, as described below.

Fourth, we avoided the garbage-in/garbage-out problem by using peer-reviewed articles and/or unpublished data sets from studies using similar procedures/materials conducted in the same labs. Although the number of suitable studies was modest, it is not unprecedented (Bodner, Taikh and Fawcett 2014; Fawcett 2013). Moreover, this number was sufficient both for confirming known findings (see Fig. 3) and for establishing 
Memory information $\left(d^{\prime}\right)$ for critical items from distinctive lists: Between - Within

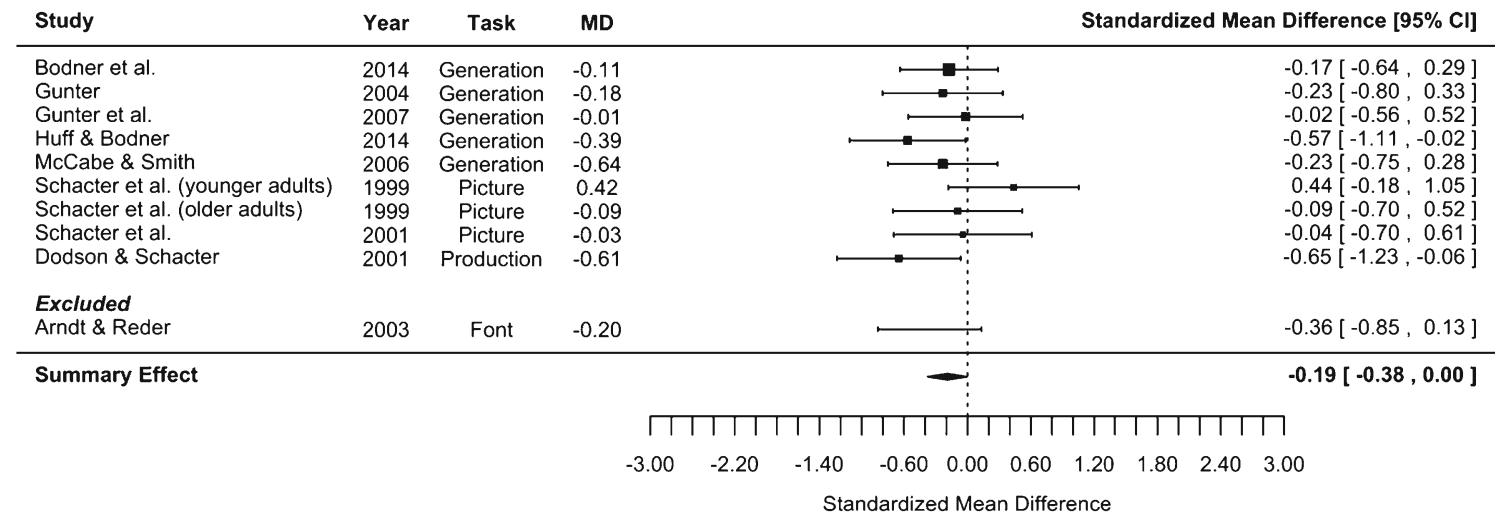

Memory information $\left(d^{\prime}\right)$ for critical items from nondistinctive lists: Between - Within

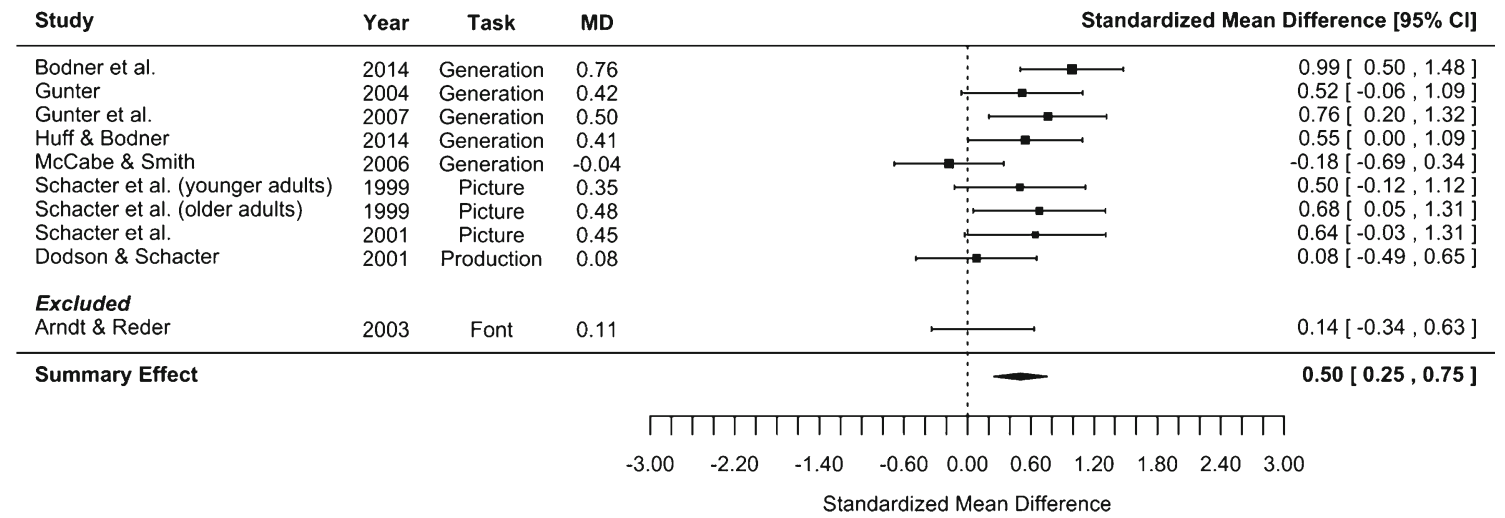

Fig. 5 Meta analyses of the influence of design on memory information for critical items from distinctive lists (Dlists; top) and nondistinctive lists (NDlists; bottom). Effect sizes and confidence intervals are based on standardized mean differences in a given index. The polygon at the

new findings as outlined above. Of course, it would be valuable to update the current meta-analyses once the available sample of studies dictates.

Using signal detection indices to isolate encoding and retrieval effects

Using signal detection indices, we revisited previous evidence for the impoverished relational encoding and distinctiveness heuristic accounts. We confirmed that studies reporting evidence for use of a distinctiveness heuristic at test (Dodson and Schacter 2001; McCabe and Smith 2006; Schacter et al. 2001; Schacter et al. 1999) indeed yield higher levels of monitoring when signal detection analyses are applied, consistent with the authors' original claims. Importantly, however, our analyses also revealed an encoding locus (in line with the impaired relational encoding claim) that was not detected in these individual studies.

To highlight one example of the merits of our signal detection approach, it prompts a reinterpretation of Schacter et al.'s (1999) findings. In their study, younger and older adults studied DRM lists in word and picture (distinctive condition) bottom of each panel represents the summary effect for each analysis, calculated using a random-effects model, excluding Arndt and Reder (2003; see Footnote 2). The square marker size indicates weight within the model. $\mathrm{MD}=$ mean difference as represented in Table 1

or word-only (nondistinctive) modalities in between and within designs. False recognition of critical items was reduced in the distinctive (vs. nondistinctive) group for both younger and older adults (see Table 2). Within subjects, false recognition was equivalently low for both list types for both age groups, leading the authors to conclude that the older adults benefited from a distinctiveness heuristic as much as younger adults.

Application of our signal detection analysis to the group level means in the between groups instead suggests a divergent pattern across the age groups. ${ }^{5}$ For younger adults, the distinctiveness heuristic account was upheld: Memory information $\left(d^{\prime}\right)$ for critical lures was similar across the distinctive and nondistinctive groups, and memory monitoring $(\lambda)$ was numerically greater in the distinctive group. For older adults, however, signal detection analyses revealed the opposite pattern: Memory information for critical lures was numerically lower in the distinctive group, and memory monitoring was

\footnotetext{
${ }^{5}$ These indices were based on the published group-level means and, hence, could not be analyzed. As a result, these numerical patterns should be interpreted with caution.
} 
similar. In other words, the false memory reduction for older adults was due to encoding processes (e.g., impoverished relational encoding), rather than to an increase in memory monitoring at test. Although inconsistent with the conclusions drawn by Schacter et al. (1999), the older adult pattern revealed by our signal detection indices is more consistent with the memory and aging literature. Specifically, older adults often show deficits in source monitoring at test (Dywan and Jacoby 1990; Hashtroudi et al. 1990), which would likely also impair their ability to monitor diagnostic details at test and, hence, to benefit from use of a distinctiveness heuristic.

The signal detection approach was also used to gauge the costs/benefits of distinctive encoding in a within design (after Begg and Snider 1987; Bodner, Taikh and Fawcett 2014). Our analyses revealed that distinctive encoding can produce costs, in contrast to Dodson and Schacter's (2002) surmise that a distinctiveness heuristic provides a cost-free memory strategy. Specifically, more memory information about critical items was encoded for distinctive lists in a within (vs. between) design. Given this finding, implementing distinctive encoding for all studied items may be more effective at reducing false recognition than implementing it on a subset of studied items. This pattern stands in curious opposition to the general finding that distinctive encoding tasks are often more effective in within designs (see McDaniel and Bugg 2008). Whether the DRM paradigm is anomalous in this respect becomes an interesting area for future research to explore.

Our signal detection analysis approach is not without potential drawbacks. Most obviously, the indices are offline, indirect estimates used to infer the presence of encoding and retrieval processes. In addition, using lambda as a quantitative metric of test-based monitoring is discordant with the qualitative aspects of monitoring that are assumed to occur when a distinctiveness heuristic strategy is applied at test. Also, our memory-monitoring measure can detect quantitative differences only in the efficacy of what participants monitor at test; it cannot determine which specific memorial detail or details they monitor. Of course, this criticism equally applies to other means used for contrasting encoding versus retrieval bases for distinctiveness effects - namely, the use of inclusion instructions and within designs (for a discussion, see Huff and Bodner 2013). Lambda will be unable to detect whether participants in different conditions monitor for different but equally diagnostic recollected details.

Despite these shortcomings, the ability to independently estimate encoding and retrieval processes is advantageous, and we advocate this approach for separating the encoding and retrieval contributions of other encoding tasks and in other memory paradigms. Powerful memory manipulations such as spacing (Balota et al. 2007; Crowder 1976; Glenberg 1977), retrieval practice (Roediger and Karpicke 2006), and survival processing (Nairne et al. 2007) have generated effects that have been attributed to encoding and/or retrieval processes.
The relative contributions of each locus, at least in recognition tasks, can fruitfully be examined through signal detection analyses. Of note, these memory effects are also generally larger in within than in between designs, suggesting that both costs and benefits may contribute to the within effects. Determining how design type influences the utility of other encoding manipulations is worthy of research attention.

An additional question is whether encoding and retrieval processes as shown in recognition would also occur in other explicit memory tasks - most notably, free recall—especially if a generate-recognize process guides recall (Anderson and Bower 1972). There is reason to believe that distinctiveness effects may be smaller in recall than in recognition due to recognition's greater sensitivity to item-specific encoding processes (McDaniel, Waddill, \& Einstein, 1988). The challenge to separating encoding and retrieval processes in recall would be the inability to use lambda to assess monitoring at retrieval. Recall metrics such as clustering (Roenker et al. 1971) or conditional response probabilities (Kahana 1996) also do not provide independent estimates of encoding and retrieval parameters. Thus, important questions for future research include how to separate and assess the encoding and retrieval processes operating in recall and whether recall produces similar patterns of costs and benefits across between and within designs.

\section{Conclusion}

We suggest that meta-analysis of signal-detection indices provides a useful tool for examining encoding and retrieval processes and their effects on correct and false recognition. Our analyses revealed that reductions in the DRM illusion following distinctive encoding arise from a combination of encoding processes (i.e., reduced relational processing at study) and retrieval processes (i.e., increased strategic monitoring for critical items at test). Furthermore, use of a within (vs. between) design was found not to be "cost free" after all; although it reduced false recognition for nondistinctive lists, it inflated false recognition for distinctive lists. Researchers therefore need to exercise caution in extrapolating the results of particular study designs to general recommendations for encoding strategies for learners.

Acknowledgments This study was supported by NIH grant 5T32AG00000-38 to M.J.H. and by a Natural Sciences and Engineering Research Council of Canada Discovery Grant to G.E.B. We extend special thanks to researchers who provided their data and to Colin MacLeod for helpful comments on an earlier draft.

Open Access This article is distributed under the terms of the Creative Commons Attribution License which permits any use, distribution, and reproduction in any medium, provided the original author(s) and the source are credited. 


\section{Appendix}

Table 2 Recognition means for between and within designs and for distinctive (D) and nondistinctive (ND) lists, and effects of design by list type and list type by design

\begin{tabular}{|c|c|c|c|c|c|c|c|c|}
\hline \multirow[b]{2}{*}{ Task/Study/Means } & \multicolumn{2}{|c|}{ Between (B) } & \multicolumn{2}{|c|}{ Within (W) } & \multicolumn{2}{|c|}{ Design Effect $(\mathrm{B}-\mathrm{W})$} & \multicolumn{2}{|c|}{ List Effect (Dlists - NDlists) } \\
\hline & Dlists & NDlists & Dlists & NDlists & Dlists & NDlists & Between & Within \\
\hline
\end{tabular}

\section{Generation}

Bodner, Huff, Gunter, \& Azad (2014) ${ }^{\mathrm{a}}$

\begin{tabular}{|c|c|c|c|c|c|c|c|c|}
\hline List items & .85 & .77 & .88 & .69 & -.03 & .07 & .09 & .19 \\
\hline List item controls & .09 & .12 & .11 & -.03 & .01 & -.03 & & \\
\hline Critical items & .49 & .68 & .56 & .51 & -.07 & .17 & -.19 & .05 \\
\hline Critical item controls & .15 & .18 & .16 & -.02 & .02 & -.03 & & \\
\hline \multicolumn{9}{|l|}{ Gunter (2004) } \\
\hline List items & .90 & .79 & .93 & .69 & -.03 & .10 & .11 & .24 \\
\hline List item controls & .10 & .21 & .13 & -.03 & .08 & -.11 & & \\
\hline Critical items & .45 & .75 & .56 & .51 & -.11 & .24 & .30 & -.05 \\
\hline Critical item controls & .15 & .32 & .25 & -.10 & .07 & -.17 & & \\
\hline \multicolumn{9}{|c|}{ Gunter, Bodner, \& Azad (2007) } \\
\hline List items & .85 & .79 & .92 & .70 & -.07 & .09 & .06 & .22 \\
\hline List item controls & .07 & .12 & .12 & -.05 & .00 & -.05 & & \\
\hline Critical items & .44 & .68 & .55 & .49 & -.11 & .17 & -.24 & .06 \\
\hline Critical item controls & .10 & .20 & .19 & -.08 & .02 & -.10 & & \\
\hline \multicolumn{9}{|l|}{ Huff and Bodner (2014) } \\
\hline List items & .84 & .75 & .90 & .60 & -.06 & .15 & .09 & .30 \\
\hline List item controls & .06 & .11 & .12 & -.06 & -.01 & -.05 & & \\
\hline Critical items & .39 & .63 & .60 & .46 & -.21 & .17 & -.24 & .14 \\
\hline Critical item controls & .09 & .17 & .13 & -.04 & .04 & -.08 & & \\
\hline \multicolumn{9}{|l|}{ McCabe and Smith (2006) } \\
\hline List items & .88 & .82 & .85 & .76 & .03 & .06 & .06 & .09 \\
\hline List item controls & .13 & .13 & .17 & -.04 & -.04 & .00 & & \\
\hline Critical items & .59 & .76 & .73 & .75 & -.14 & .01 & -.17 & -.02 \\
\hline Critical item controls & .20 & .18 & .21 & -.01 & -.03 & .02 & & \\
\hline
\end{tabular}

Pictures

Schacter, Israel, \& Racine (1999; younger adult group)

$\begin{array}{llll}\text { List items } & .78 & .79 & .83 \\ \text { List item controls } & .09 & .21 & .17 \\ \text { Critical items } & .35 & .66 & .47 \\ \text { Critical item controls } & .08 & .28 & .25\end{array}$

Schacter et al. (1999; older adult group)

$\begin{array}{llll}\text { List items } & .71 & .72 & .77 \\ \text { List item controls } & .08 & .28 & .2 \\ \text { Critical items } & .46 & .72 & .63 \\ \text { Critical item controls } & .16 & .17 & .26\end{array}$

$\begin{array}{lll}-.17 & .03 & -.20\end{array}$

Schacter, Cendan, Dodson, \& Clifford (2001)

$\begin{array}{llll}\text { List items } & .64 & .67 & .70 \\ \text { List item controls } & .05 & .14 & .08 \\ \text { Critical items } & .27 & .56 & .36 \\ \text { Critical item controls } & .03 & .18 & .16\end{array}$

Production 
Table 2 (continued)

\begin{tabular}{|c|c|c|c|c|c|c|c|c|}
\hline \multirow[b]{2}{*}{ Task/Study/Means } & \multicolumn{2}{|c|}{ Between (B) } & \multicolumn{2}{|c|}{ Within (W) } & \multicolumn{2}{|c|}{ Design Effect $(\mathrm{B}-\mathrm{W})$} & \multicolumn{2}{|c|}{ List Effect (Dlists - NDlists) } \\
\hline & Dlists & NDlists & Dlists & NDlists & Dlists & NDlists & Between & Within \\
\hline \multicolumn{9}{|c|}{ Dodson and Schacter (2001) } \\
\hline List items & .76 & .71 & .79 & .70 & -.03 & .01 & .05 & .09 \\
\hline List item controls & .16 & .16 & .12 & -.04 & -.04 & .00 & & \\
\hline Critical items & .51 & .72 & .58 & .57 & -.07 & .15 & -.21 & .01 \\
\hline Critical item controls & .28 & .29 & .14 & .14 & -.15 & -.01 & & \\
\hline \multicolumn{9}{|l|}{ Font } \\
\hline \multicolumn{9}{|l|}{ Arndt and Reder $(2003)^{\mathrm{b}}$} \\
\hline List items & .87 & .89 & .90 & .93 & -.03 & -.04 & -.02 & -.03 \\
\hline List item controls & .12 & .10 & .14 & -.02 & -.04 & .02 & & \\
\hline Critical items & .48 & .77 & .54 & .77 & -.06 & .00 & -.29 & -.23 \\
\hline Critical item controls & .20 & .19 & .19 & .01 & .00 & .01 & & \\
\hline \multicolumn{9}{|c|}{ Average (excluding Arndt and Reder 2003) } \\
\hline List items & .80 & .76 & .84 & .68 & -.04 & .07 & .04 & .16 \\
\hline List item controls & .09 & .16 & .14 & -.05 & .03 & -.07 & & \\
\hline Critical items & .44 & .68 & .56 & .53 & -.12 & .15 & -.25 & .03 \\
\hline Critical item controls & .14 & .22 & .19 & -.06 & .02 & -.08 & & \\
\hline
\end{tabular}

${ }^{a}$ Dlists collapsed across generation and self-imagery tasks.

${ }^{\mathrm{b}}$ Dlists collapsed across the uncorrelated and unique font groups; NDlists is the correlated font group.

\section{References}

Anderson, J. R., \& Bower, G. H. (1972). Recognition and retrieval processes in free recall. Psychological Review, 72, 98-123.

Arndt, J., \& Reder, L. M. (2003). The effect of distinctive visual information on false recognition. Journal of Memory and Language, 48, 1-15. doi:10.1016/S0749-596X(02)00518-1

Balota, D. A., Duchek, J. M., \& Logan, J. M. (2007). Is expanded retrieval practice a superior form of spaced retrieval? A critical review of the extant literature. In J. S. Nairne (Ed.), The Foundations of Remembering: Essays in honor of Henry L. Roediger, III (pp. pp. 83-105). New York: Psychology Press.

Begg, I., \& Snider, A. (1987). The generation effect: Evidence for generalized inhibition. Journal of Experimental Psychology. Learning, Memory, and Cognition, 13, 553-563. doi:10.1037/0278-7393.13.4.553

Begg, I., Snider, A., Foley, F., \& Goddard, R. (1989). The generation effect is no artifact: Generating makes words distinctive. Journal of Experimental Psychology. Learning, Memory, and Cognition, 15, 977-989. doi:10.1037/0278-7393.15.5.977

Benjamin, A. S. (2001). On the dual effects of repetition on false recognition. Journal of Experimental Psychology. Learning, Memory, and Cognition, 27, 941-947. doi:10.1037/0278-7393.27.4.941

Bertsch, S., Pesta, B. J., Wiscott, R., \& McDaniel, M. A. (2007). The generation effect: A meta-analytic review. Memory \& Cognition, 35, 201-210. doi:10.3758/BF03193441

Bodner, G. E., Huff, M. J., Gunter, R. W., \& Azad, T. (2014). Do differences in distinctiveness or memory strength dampen the DRM illusion? Manuscript in preparation.

Bodner, G. E., \& Taikh, A. (2012). Reassessing the basis of the production effect in memory. Journal of Experimental Psychology. Learning, Memory, and Cognition, 38, 1711-1719. doi:10.1037/a0028466

Bodner, G. E., Taikh, A., \& Fawcett, J. M. (2014). Assessing the costs and benefits of production in recognition. Psychonomic Bulletin \& Review, 21, 149-154. doi:10.3758/s13423-013-0485-1
Borenstein, M. (2009). Effect sizes for continuous data. In H. Cooper, L. V. Hedges, \& J. C. Valentine (Eds.), The Handbook of Research Synthesis and Meta-analysis (2nd ed., pp. 221-226). New York: Russell Sage Foundation.

Brainerd, C. J., Payne, D. G., Wright, R., \& Reyna, V. F. (2003). Phantom recall. Journal of Memory and Language, 48, 445-467. doi:10. 1016/S0749-596X(02)00501-6

Brainerd, C. J., \& Reyna, V. F. (2002). Fuzzy-trace theory and false memory. Current Directions in Psychological Science, 11, 164 169. doi:10.1111/1467-8721.00192

Craik, F. I. M., \& Lockhart, R. S. (1972). Levels of processing: A framework for memory research. Journal of Verbal Learning \& Verbal Behavior, 11, 671-684. doi:10.1016/S0022-5371(72)80001-X

Crowder, R. G. (1976). Principles of Learning and Memory. Hillsdale: Lawrence Erlbaum Associates.

Deese, J. (1959). On the prediction of occurrence of particular verbal intrusions in immediate recall. Journal of Experimental Psychology, 58, 17-22. doi:10.1037/h0046671

Dodson, C. S., \& Schacter, D. L. (2001). "If I had said it I would have remembered it": Reducing false memories with a distinctiveness heuristic. Psychonomic Bulletin \& Review, 8, 155-161. doi:10. 3758/BF03196152

Dodson, C. S., \& Schacter, D. L. (2002). When false recognition meets metacognition: The distinctiveness heuristic. Journal of Memory and Language, 46, 782-803. doi:10.1006/jmla.2001.2822

Dunlosky, J., Hunt, R. R., \& Clark, E. (2000). Is perceptual salience needed in explanations of the isolation effect? Journal of Experimental Psychology: Learning, Memory, \& Cognition, 26, 649-657. doi:10.1037/0278-7393.26.3.649

Duval, S. (2005). The trim and fill method. In R. Rothstein, A. Sutton, \& M. Borenstein (Eds.), Publication Bias in Meta-Analysis: Prevention, Assessments, Adjustments (pp. 127-144). Chichester: Wiley.

Dywan, J., \& Jacoby, L. (1990). Effects of aging on source monitoring: Differences in susceptibility to false fame. Psychology and Aging, 5, 379-387. doi:10.1037/0882-7974.5.3.379 
Fawcett, J. M. (2013). The production effect benefits performance in between-subjects designs: A meta-analysis. Acta Psychologica, 142, 1-5. doi:10.1016/j.actpsy.2012.10.001

Gallo, D. A. (2004). Using recall to reduce false recognition: Diagnostic and disqualifying monitoring. Journal of Experimental Psychology. Learning, Memory, and Cognition, 30, 120-128. doi:10.1037/02787393.30 .1 .120

Gallo, D. A. (2006). Associative memory illusions. New York: Psychology Press.

Gallo, D. A. (2010). False memories and fantastic beliefs: 15 years of the DRM illusion. Memory \& Cognition, 38, 833-848. doi:10.3758/ MC.38.7.833

Gallo, D. A., Roediger, H. L., III, \& McDermott, K. B. (2001). Associative false recognition occurs without strategic criterion shifts. Psychonomic Bulletin \& Review, 8, 579-586. doi:10.3758/ BF03196194

Glanzer, M., \& Adams, J. K. (1990). The mirror effect in recognition memory: Data and theory. Journal of Experimental Psychology. Learning, Memory, and Cognition, 16, 5-16. doi:10.1037/02787393.16.1.5

Glenberg, A. M. (1977). Influences of retrieval processes on the spacing effect in free recall. Journal of Experimental Psychology: Human Learning and Memory, 3, 282-294. doi:10.1037/0278-7393.3.3.282

Geraci, L., \& Rajaram, S. (2002). The orthographic distinctiveness effect on direct and indirect tests of memory: Delineating the awareness and processing requirements. Journal of Memory and Language, 47, 273-291. doi:10.1016/S0749-596X(02)00008-6

Gunter, R. W. (2004). Using generation to improve memory accuracy in a false recognition paradigm. Unpublished Master's Thesis, University of Calgary.

Gunter, R. W., Bodner, G. E., \& Azad, T. (2007). Generation and mnemonic encoding induce a mirror effect in the DRM paradigm. Memory \& Cognition, 35, 1083-1092. doi:10.3758/BF03193480

Hashtroudi, S., Johnson, M. K., \& Chrosniak, L. D. (1990). Aging and qualitative characteristics of memories for perceived and imagined complex events. Psychology and Aging, 5, 119-126. doi:10.1037/ 0882-7974.5.1.119

Hedges, L. V. (1981). Distribution theory for Glass's estimator of effect size and related estimators. Journal of Educational Statistics, 6, 107-128. doi:10.2307/1164588

Hedges, L. V., \& Olkin, I. (1985). Statistical Methods for Meta-Analyses. New York: Academic Press.

Hege, A. C. G., \& Dodson, C. S. (2004). Why distinctive information reduces false memories: Evidence for both impoverished relationalencoding and distinctiveness heuristic. Journal of Experimental Psychology. Learning, Memory, and Cognition, 30, 787-795. doi: 10.1037/0278-7393.30.4.787

Higgins J.P.T., \& Green S. (2009). Cochrane Handbook for Systematic Reviews of Interventions Version 5.0.2 [updated September 2009]. The Cochrane Collaboration. Available from www.cochranehandbook.org

Hockley, W. E., \& Cristi, C. (1996). Tests of encoding tradeoffs between item and associative information. Memory \& Cognition, 24, 202 216. doi:10.3758/BF0320081

Hopkins, R. H., \& Edwards, R. E. (1972). Pronunciation effects in recognition memory. Journal of Verbal Learning and Verbal Behavior, 11, 534-537.

Huff, M. J., \& Bodner, G. E. (2013). When does memory monitoring succeed versus fail? Comparing item-specific and relational encoding in the DRM paradigm. Journal of Experimental Psychology. Learning, Memory, and Cognition, 39, 1246-1256. doi: $10.1037 / \mathrm{a} 0031338$

Huff, M. J., \& Bodner, G. E. (2014). Comparing item-specific and relational generation tasks in the DRM paradigm using between- and within-subjects designs. Manuscript in preparation
Hunt, R. R. (2006). The concept of distinctiveness in memory research. In R. R. Hunt \& J. B. Worthen (Eds.), Distinctiveness and Memory (pp. 3-25). New York: Oxford University Press.

Hunt, R. R., \& Einstein, G. O. (1981). Relational and item-specific information in memory. Journal of Verbal Learning \& Verbal Behavior, 20, 497-514. doi:10.1016/S0022-5371(81)90138-9

Hunt, R. R., \& Worthen, J. B. (2006). Distinctiveness and Memory. New York: Oxford University Press.

Hunt, R. R., Smith, R. E., \& Dunlap, K. R. (2011). How does distinctive processing reduce false recall? Journal of Memory and Language, 65, 378-389. doi:10.1016/j.jml.2011.06.003

Israel, L., \& Schacter, D. L. (1997). Pictorial encoding reduces false recognition of semantic associates. Psychonomic Bulletin \& Review, 4, 577-581.

Jenkins, W. O., \& Postman, L. (1948). Isolation and the spread effect in serial learning. American Journal of Psychology, 61, 214-221. doi: $10.2307 / 1416967$

Joordens, S., \& Hockley, W. E. (2000). Recollection and familiarity through the looking glass: When old does not mirror new. Journal of Experimental Psychology. Learning, Memory, and Cognition, 26, 1534-1555. doi:10.1037/0278/-7393.26.6.1534

Kahana, M. J. (1996). Associative retrieval processes in free-recall. Memory \& Cognition, 24, 103-109.

Kelley, M. R., \& Nairne, J. S. (2001). von Restorff revisited: Isolation, generation, and memory for order. Journal of Experimental Psychology. Learning, Memory, and Cognition, 27, 54-66. doi:10. 1037/0278/7393.27.1.54

MacLeod, C. M., Gopie, N., Hourihan, K. L., Neary, K. R., \& Ozubko, J. D. (2010). The production effect: Delineation of a phenomenon. Journal of Experimental Psychology. Learning, Memory, and Cognition, 36, 671-685. doi:10.1037/a0018785

Macmillan, N. A., \& Creelman, C. D. (1991). Detection theory: A user's guide. New York: Cambridge University Press.

McCabe, D. P., \& Smith, A. D. (2002). The effect of warnings on false memories in young and older adults. Memory \& Cognition, 30, 1065-1077. doi:10.3758/BF03194324

McCabe, D. P., \& Smith, A. D. (2006). The distinctiveness heuristic in false recognition and false recall. Memory, 14, 570-583. doi:10. 1080/09658210600624564

McDaniel, M. A., \& Bugg, J. M. (2008). Instability in memory phenomena: A common puzzle and a unifying explanation. Psychonomic Bulletin \& Review, 15, 237-255. doi:10.3758/ PBR.15.2.237

McDaniel, M. A., \& Einstein, G. O. (1991). Bizarre imagery: Mnemonic benefits and theoretical implications. In R. H. Logie \& M. Denis (Eds.), Mental Images in Human Cognition (pp. 183-192). Amsterdam: Elsevier.

McDaniel, M. A., \& Geraci, L. (2006). Encoding and retrieval processes in distinctiveness effects: Toward an integrative framework. In R. R. Hunt \& J. B. Worthen (Eds.), Distinctiveness and Memory (pp. 6588). New York, NY: Oxford University Press.

McDaniel, M. A., Waddill, P. J., \& Einstein, G. O. (1988). A contextual account of the generation effect: A threefactor theory. Journal of Memory and Language, 27, 521-536. doi: 10.1016/0749-596X(88) 90023-X

McDermott, K. B. (1996). The persistence of false memories in list recall. Journal of Memory and Language, 35, 212-230. doi:10.1006/jmla. 1996.0012

Nairne, J. S., Thompson, S. R., \& Pandeirada, J. N. S. (2007). Adaptive memory: Survival processing enhances retention. Journal of Experimental Psychology. Learning, Memory, and Cognition, 33, 263-273. doi:10.1037/0278-7393.33.2.263

Pierce, B. H., Gallo, D. A., Weiss, J. A., \& Schacter, D. L. (2005). The modality effect in false recognition: Evidence for test-based monitoring. Memory \& Cognition, 33, 1407-1413. doi:10.3758/ BF03193373 
Pigott, T. D. (2009). Handling missing data. In H. Cooper, L. V. Hedges, \& J. C. Valentine (Eds.), The Handbook of Research Synthesis and Meta-analysis (2nd ed., pp. 399-416). New York: Russell Sage Foundation.

R Development Core Team. (2013). R: A language and environment for statistical computing. Vienna: R Development Core Team.

Roediger, H. L., III, Balota, D. A., \& Watson, J. M. (2001). Spreading activation and arousal of false memories. In H. L. Roediger, J. S. Nairne, I. Neath, \& A. M. Surprenant (Eds.), The nature of remembering: Essays in honor of Robert G. Crowder (pp. pp. 95-115). Washington: American Psychological Association. doi:10.1037/10394-00

Roediger, H. L., III, \& McDermott, K. B. (1995). Creating false memories: Remembering words not presented in lists. Journal of Experimental Psychology. Learning, Memory, and Cognition, 21, 803-814. doi:10.1037/0878-7393.21.4.803

Roediger, H. L., III, \& Karpicke, J. D. (2006). Test enhanced learning: Taking memory tests improves long-term retention. Psychological Science, 17, 249-255. doi:10.1111/j.1467-9280.2006.01693

Roenker, D. L., Thompson, C. P., \& Brown, S. C. (1971). Comparison of measures for the estimation of clustering in free recall. Psychological Bulletin, 76, 45-48. doi:10.1037/h0031355

Rosenthal, R., \& Dimatteo, M. R. (2002). Meta-analysis. In H. Pashler, \& J. Wixted (Eds.), Stevens Handbook of Experimental Psychology (3rd Ed.), Volume 4: Methodology in Experimental Psychology. (pp. 391-428). Hoboken: John Wiley \& Sons, Inc.

Schacter, D. L., Cendan, D. L., Dodson, C. S., \& Clifford, E. R. (2001). Retrieval conditions and false recognition: Testing the distinctiveness heuristic. Psychonomic Bulletin \& Review, 8, 827-833. doi:10. 3758/BF03196224

Schacter, D. L., Israel, L., \& Racine, C. (1999). Suppressing false recognition in younger and older adults: The distinctiveness heuristic. Journal of Memory and Language, 40, 1-24. doi:10.1006/jmla.1998.2611

Schmidt, S. R. (1991). Can we have a distinctive theory of memory? Memory \& Cognition, 19, 523-545. doi:10.3758/BF03197149

Slamecka, N. J., \& Graf, P. (1978). The generation effect: Delineation of a phenomenon. Journal of Experimental Psychology: Human Learning and Memory, 4, 592-604. doi: 10.1037/0278-7393.4.6.592

Viechtbauer, W. (2010). Conducting meta-analyses in R with the metafor package. Journal of Statistical Software, 36, 1-48.

von Restorff, H. (1933). Uber de Wirkung Bereichsblidungen im Spurenfeld. Psychologishe Forschung, 18, 299-342.

Waddill, P. J., \& McDaniel, M. A. (1998). Distinctiveness effects in recall: Differential processing or privileged retrieval? Memory \& Cognition, 26, 108-120. doi:10.3758/BF03211374

Wickens, T. D. (2002). Elementary signal detection theory. New York: Oxford University Press. 